the heat produced and increased net carbon sequestration by expanded plantings. Integrating farmed forestry plantations and woody energy crops within current farming areas would increase biomass supply without disrupting water run-off or the production of food and fibre. Fewer conventional watercooled power plants would also mean reduced consumption of potable water.

Andrew Lang SMARTimbers Cooperative, Ballarat, Australia. Heinz Kopetz Austrian Biomass Association, Vienna, Austria. Albert Parker University of Ballarat, Ballarat, Australia. albertparker@y7mail.com

\section{Curb temptation to skip quality control}

Daniel MacArthur cautions scientists and journal editors against jumping to "false positive" conclusions (Nature 487, 427-428; 2012). But temptations to leap over the quality-control gap are rife in scientific publishing.

Journals are proliferating, even in the top tier, so they have to compete for eye-catching papers. The quality of these publications necessarily depends on the vanishing time of a small pool of expert reviewers. Those who are competent in statistics are in particularly short supply.

Authors are driven to publish in the leading journals so that they can reap the benefits of academic respect, such as promotion and tenure. Never mind being overly conscientious in underpinning the conclusions - refuted results do not always end in retraction. And if a paper is retracted, it may not always have serious repercussions.

The upshot is that ambitious researchers want to push the limits of credibility in interpreting their results, and the same can be said of journal editors.

This publication 'currency' needs to be brought under tighter control to curb inflationary practices among authors and editors.

Herman Tse University of Hong Kong, Hong Kong. herman@graduate.hku.hk

\section{Speed up reviews of misconduct}

We call for greater transparency and speed in investigations of scientific misconduct. For the benefit of the scientific community, swift assessment of the validity of published results should be distinguished from legally convoluted verdicts that concern wilful deceit.

Journal publishers and academic institutions have differed markedly in their response to recent cases of alleged misconduct. For example, the committee investigating publications by the Dutch social psychologist Diederik Stapel (Nature 479, 15; 2011) published an interim report within two months and is releasing its findings in under a year (www.commissielevelt.nl). And a panel investigating the papers of another social psychologist, Dirk Smeesters (Nature 487, 18; 2012), reported its results within a week of his resignation. Such prompt and detailed reporting contrasts with that of other protracted enquiries that have culminated in retractions of papers.

Web-based initiatives such as Retraction Watch (www. retractionwatch.com) can help by offering timely, although informal, alerts about suspect papers. Even if fabrication or falsification cannot be proved beyond reasonable doubt, statistical indications of problems with the data - such as gross errors or remarkably consistent findings - are scientifically relevant.

Jelte M. Wicherts, Marcel A. L. M. van Assen Tilburg University, the Netherlands. j.m.wicherts@uvt.nl

\section{PhDs fit for industry and commerce, too}

You continue to lament the shortcomings of $\mathrm{PhD}$ training (see, for example, Nature 472, 259-260; 2011 and Nature 486, 304 ; 2012) but overlook the encouraging results of reforms to $\mathrm{PhD}$ programmes in many European countries.

Programmes in the region

have modernized, expanding the traditional apprenticeship model in recognition of the fact that most new $\mathrm{PhDs}$ are not destined for academia. Industry and commerce are already welcoming this new batch of graduates.

Training has been broadened to develop such skills as scientific and lay presentation, teaching, grant application, time management, linguistic abilities and networking. These complement the rigour acquired in setting up and completing a three-year research project, and are valuable in any job that demands creative synthesis and the use of initiative, whether inside or outside academia. Flying in the face of convention, students can delegate some of their $\mathrm{PhD}$ work and learn how to become managers.

These reforms are being promoted by the European Commission, the European Universities Association Council for Doctoral Education (see, for example, Nature 468, 125; 2010 and Nature 482, 557-559; 2012) and by ORPHEUS, an independent organization that represents more than 100 European biomedical and medical faculties (www.orpheusmed.org).

Michael Mulvany ORPHEUS, Aarhus University, Denmark. mm@farm.au.dk

Zdravko Lackovic ORPHEUS, University of Zagreb School of Medicine, Croatia.

\section{Institute to continue climate monitoring}

Contrary to what you imply in your online News article, staff cuts are not sounding a "death knell" for the Lauder research station run by the National Institute of Water and Atmospheric Research (NIWA) in New Zealand (http://doi. org/h65). We at NIWA reaffirm the institute's commitment to continuing its long-term atmospheric measurements, which are crucial for climate research.

NIWA sites at Lauder and Arrival Heights, Antarctica, will maintain their multi-instrument measurement programmes to monitor radiation, ozone and a range of atmospheric trace gases. National and international scientific expertise will continue to oversee and support these activities. NIWA is increasing its investment in instrumental capacity at both sites, and is continuing the long-term observations made on behalf of overseas institutions.

The review of NIWA's Lauder staff retains three of six atmospheric-scientist positions and the five technicians, and creates one new measurementscientist post; two of the departing scientists will still take part in an emeritus capacity. A measurement scientist and a technician based at other NIWA sites will lend further support.

The review outcome is a reprioritization in favour of long-term monitoring, rather than a major change in Lauder's research direction (see go.nature. com/vnnb37).

Olaf Morgenstern, Richard McKenzie, Vanessa Sherlock National Institute of Water and Atmospheric Research, New Zealand. olaf.morgenstern@niwa.co.nz

\section{Embrace complexity but not jargon}

In advocating that science writers should not shun scientific jargon, Trevor Quirk proposes the wrong means to the right end for improving science communication (Nature 487, 407; 2012)

The science writer's tough task is to help readers to grasp the nuances and complex concepts behind obscure specialist terminology by translating it into simple, accurate language. There is nothing patronizing about this. Esoteric terms can develop in any discipline - even some Olympic sports use mysterious labels such as 'keirin' and 'repechage'. And the general reader should not be expected to decode words used by scientists who have years of training under their belts.

The public benefits from skilful clarification, as do scientists.

Anita Makri The Science and Development Network (SciDev. Net), London, UK. anita.makri@scidev.net 